\title{
Moving into Protected Areas? Setting Conservation Priorities for Romanian Reptiles and Amphibians at Risk from Climate Change
}

\author{
Viorel D. Popescu ${ }^{1,2 *}$, Laurențiu Rozylowicz², Dan Cogălniceanu ${ }^{3}$, lulian Mihăiță Niculae ${ }^{2}$, Adina Livia \\ Cucu $^{2}$
}

1 Earth to Ocean Research Group, Department of Biological Sciences, Simon Fraser University, Burnaby, British Columbia, Canada, 2 Centre for Environmental Research (CCMESI), University of Bucharest, Bucharest, Romania, 3 Faculty of Natural and Agricultural Sciences, University Ovidius Constanța, Constanța, Romania

\begin{abstract}
Rapid climate change represents one of the top threats to biodiversity, causing declines and extinctions of many species. Range shifts are a key response, but in many cases are incompatible with the current extent of protected areas. In this study we used ensemble species distribution models to identify range changes for 21 reptile and 16 amphibian species in Romania for the 2020s and 2050s time horizons under three emission scenarios (A1B = integrated world, rapid economic growth, $\mathrm{A} 2 \mathrm{~A}=$ divided world, rapid economic growth [realistic scenario], $\mathrm{B} 2 \mathrm{~A}=$ regional development, environmentally-friendly scenario) and no- and limited-dispersal assumptions. We then used irreplaceability analysis to test the efficacy of the Natura 2000 network to meet conservation targets. Under all scenarios and time horizons, $90 \%$ of the species suffered range contractions (greatest loses under scenarios B2A for 2020s, and A1B for 2050s), and four reptile species expanded their ranges. Two reptile and two amphibian species are predicted to completely lose climate space by 2050 s. Currently, 35 species do not meet conservation targets ( $>40 \%$ representation in protected areas), but the target is predicted to be met for $4-14$ species under future climate conditions, with higher representation under the limited-dispersal scenario. The Alpine and Steppic-Black Sea biogeographic regions have the highest irreplaceability value, and act as climate refugia for many reptiles and amphibians. The Natura 2000 network performs better for achieving herpetofauna conservation goals in the future, owing to the interaction between drastic range contractions, and range shifts towards existing protected areas. Thus, conservation actions for herpetofauna in Romania need to focus on: (1) building institutional capacity of protected areas in the Alpine and Steppic-Black Sea biogeographic regions, and (2) facilitating natural range shifts by improving the conservation status of herpetofauna outside protected areas, specifically in traditionally-managed landscapes and abandoned cropland.
\end{abstract}

Citation: Popescu VD, Rozylowicz L, Cogălniceanu D, Niculae IM, Cucu AL (2013) Moving into Protected Areas? Setting Conservation Priorities for Romanian Reptiles and Amphibians at Risk from Climate Change. PLoS ONE 8(11): e79330. doi:10.1371/journal.pone.0079330

Editor: Olle Terenius, Swedish University of Agricultural Sciences, Sweden

Received April 15, 2013; Accepted October 1, 2013; Published November 4, 2013

Copyright: $\odot 2013$ Popescu et al. This is an open-access article distributed under the terms of the Creative Commons Attribution License, which permits unrestricted use, distribution, and reproduction in any medium, provided the original author and source are credited.

Funding: This work was supported by a grant of the Romanian National Authority for Scientific Research, CNCS - UEFISCDI (http://uefiscdi.gov.ro), project number PN-II-RU-TE-2011-3-0183. VDP was partly supported by a David H. Smith Conservation Research Fellowship from the Society for

Conservation Biology (www.smithfellows.org). The funders had no role in study design, data collection and analysis, decision to publish, or preparation of the manuscript.

Competing interests: The authors have declared that no competing interests exist.

*E-mail: vioreldpopescu@gmail.com

\section{Introduction}

Protected areas continue to be one of the main instruments in the biodiversity conservation toolbox, and the total area benefiting of legal protection has been increasing worldwide [1]. Between $10.1 \%$ and $15.5 \%$ of land area is under some form of protection worldwide [2], and at a global level protected areas have been established at a fast pace, overcoming our capacity to manage them [1]. Despite concerted efforts towards designing resilient protected areas, and implementing ecologically-relevant conservation strategies, reserve networks still fail to conserve important biodiversity elements (species- to biome-level misrepresentation) [3]. Adding to these issues, the world's current protected areas network faces additional challenges from climate change [4]. Particularly, identifying of priority areas within and outside the current protected network that are resilient to climate change is challenged by uncertainties surrounding future climate projections and species responses to climate change [5-7]. 
Climate change has already caused declines or extinctions of many amphibian and reptile species through direct effects, such as altered thermal niches, or through synergies with other threats, such as pathogens and land use changes [8,9]. A recent evaluation of the status of European herpetofauna has shown that $19 \%$ of reptiles and $23 \%$ of amphibians are threatened $[10,11]$. In the context of future climate change, range shifts are a key response, and can affect species representation in protected areas. Species vary in their dispersal potential, and limited dispersal may hinder the ability of species to track potentially suitable climate space [12]. Ectotherms are more likely to track their climate space compared to endotherms [13], and major shifts in herpetofaunal assemblages caused by climate change are predicted worldwide [14]. Thus, from a practical conservation perspective, it is critical to evaluate potential spatial mismatches between predicted range shifts of threatened reptiles and amphibians and the extent of protected areas, and evaluate emerging conservation challenges (e.g., loser species) and opportunities (e.g., winner species; sensu [15]).

The pan-European Natura 2000 protected areas network is projected as a safety net for conserving priority species and habitats. Despite existing design flaws that limit the connectedness and functional connectivity across national borders [16], the Natura 2000 network is the outcome of two of the strongest legal continental-level conservation instruments: the Habitats and Birds Directives. In 2012, the Natura 2000 network covered $17.9 \%$ of terrestrial Europe, and it is projected to reach $20 \%$ by 2020 . The designation of Natura 2000 sites is not always based on quantifiable conservation targets or comprehensive spatial planning (e.g., [17]). As such, many sites are designated simply to achieve area targets set by European Union for country-level protection (i.e., 20\% of any EU country protected in Natura 2000 network) [18]. In the context of the enlarged European Union, little attention has been paid to comprehensive conservation planning in Eastern European countries [19]. While European-level studies addressing the issue of protected areas resilience in the face of climate change exist (e.g., [15,20]), the coarse resolution of such analyses may not be useful for national-level planning.

The aim of our study is to identify conservation priorities for Romania's amphibians and reptiles in the face of climate change, using a spatial conservation planning approach. We make use of a comprehensive species occurrence dataset, which includes 19 amphibian and 23 reptile species found in Romania; of these, 10 amphibian (52.6\%) and 13 reptiles species $(56.6 \%)$ are at the limit of their geographical ranges, which increases the uncertainties for their effective conservation in the light of predicted climate-induced range shifts [21]. Using ensemble forecasting species distribution models, we evaluated how climate change and dispersal ability shape future amphibians and reptiles distributions in Romania. We then assessed species representation in the Natura 2000 network under current, as well as future climate conditions. We tested the efficacy of Natura 2000 sites for achieving European conservation targets, and identified priority areas (irreplaceability hotspots) within European biogeographic regions. We then evaluated the strength of spatial association between the existing Natura 2000 network and predicted priority areas for conservation (under current and future climate scenarios) to identify potential gaps, as well as opportunities for conservation within the current protected areas network.

\section{Materials and Methods}

\section{Species data}

For this analysis we used occurrence only data for 21 species of reptiles and 16 amphibians from the first nation-wide database of species occurrences of any taxa in Romania $[22,23]$. This database reports the location of actual occurrences, and we aggregated the data to presence/absence within $254810 \times 10 \mathrm{~km}$ cells (planning units = PUs, hereafter) based on a Universal Transverse Mercator (UTM) grid. The 10 $\times 10 \mathrm{~km}$ grid represents a standardized way of reporting Natura 2000 effectiveness [24]. According to the European Red List of reptiles [10] and amphibians [11], two amphibian (Pelobates syriacus and Triturus dobrogicus) and three reptile species (Elaphe quatuorlineata, Lacerta praticola, and Testudo hermanni) are ranked as Near Threatened, and four reptile species are ranked as Vulnerable (Emys orbicularis, Eremias arguta, Testudo graeca, and Vipera ursinii). We did not model the distributions of Rana esculenta and Rana ridibunda, which together represent a species complex difficult to distinguish in the field [25], Rana dalmatina and Eryx jaculus (both species having low number of occurrence data in our database) and Natrix natrix (the only reptile not protected under the Romanian legislation). For this analysis we used binomial nomenclature from EU Habitats Directive and Romanian legislation.

\section{Protected areas data}

The spatial data on the location/boundaries of the 374 terrestrial Sites of Community Importance ( $\mathrm{SCl}$, designated to protect habitats and species listed in EU Habitats Directive) was provided by the Romanian Ministry of Environment (www.mmediu.ro, accessed 6 October 2012). The area covered by terrestrial SCls in Romania is $40168 \mathrm{~km}^{2}(16.84 \%$ of the territory). We then selected PUs that overlapped with SCls (i.e., protected PUs) using an iterative aggregation method [4], which yielded a total area of protected PUs equal to the actual area in SCls. This procedure yielded 410 PUs (16\% of all PUs, similar to the proportion of protected areas in SCls), with a PU in protected status when $>36 \%$ of its area was contained in SCls. At European Union level, the effectiveness of Natura 2000 network is estimated based on European biogeographic regions (BGR). Romanian territory lies into five BGRs: Alpine, Continental, Pannonian, Steppic, and Black Sea [17]. For the purpose of this analysis, the Black Sea BGR was merged with the adjacent Steppic BGR due to its limited terrestrial coverage.

\section{Environmental data}

We derived a set of climate parameters for current conditions from the WorldClim dataset [26], which contains bioclimatic grids for 1950 - 2000 at a 30 arc-second resolution. Based on the life histories and known physiological requirements of our 
study species, we selected a set of nine bioclimatic variables for modeling their distribution. For amphibians, we used : (1) annual mean temperature, (2) mean diurnal range, (3) isothermality (mean temperature diurnal range/temperature annual range), (4) annual temperature range (5), mean temperature of the wettest quarter (6), precipitation of the warmest quarter, and (7) precipitation of the coldest quarter. For reptiles, we used a slightly different set of bioclimatic variables that included variables (1) - (4), as well as (8) mean annual temperature of the warmest quarter, and (9) annual precipitation. We used several moisture-related variables for amphibians because of their aquatic-terrestrial life-cycles and susceptibility to desiccation, while for reptiles the variables are mostly related to thermoregulation, with less emphasis on moisture availability. We only used variables with pairwise correlation coefficients $<0.7$. Current climate data was freely available from the WorldClim database (www.worldclim.org; accessed 10 August 2012).

Future climate projections were derived for two time horizons: 1991 - 2020 (2020's) and 2021 - 2050 (2050's) and three IPCC emission scenario families (SRES A1, A2, and B2) from the HadCM3 30-arc-second resolution climate model developed by the Climate Research Unit at the University of East Anglia [27]. Specifically, we chose scenarios A1B, A2A and B2A to capture uncertainties around climate change projections: (1) scenario A1B describes a more integrated world, with rapid economic growth and emphasis placed on all energy sources; (2) scenario A2A describes a more divided world, with regionally-oriented economic growth, increased energy and land-use changes (more realistic scenario); (3) scenario B2A describes regionally-oriented development, but with emphasis on environmental protection, and slower landuse changes (more environmentally-friendly scenario). These scenarios capture a wide range of variability in predicted $\mathrm{CO}_{2}$ emissions (between $11 \mathrm{Gt} /$ year (B2A) and $18 \mathrm{Gt} /$ year (A2A) by 2050s (http://www.ipcc.ch/ipccreports/tar/wg1/029.htm). Future climate data was freely available from the CGIAR Research Program on Climate Change, Agriculture and Food Security (http://www.ccafs-climate.org; accessed 10 August 2012).

Species distributions are broadly associated to climatic variables, but land use changes shape the current distribution of species at a local scale. Thus, including land cover variables improves the performance of species distribution models [28]. We used the 2006 CORINE land cover dataset (European Environment Agency, Copenhagen, Denmark) to extract the proportion of developed, forested, agricultural, and herbaceous lands within each $10 \times 10 \mathrm{~km}$ grid cell.

\section{Species distribution modeling}

We modeled species distributions using seven models in the bioclimatic niche modeling package BIOMOD [29] implemented in R 2.15.1 [30]. The models included: (1) generalized additive models (GAM), (2) multivariate adaptive regression splines (MARS), (3) classification tree analysis (CTA), (4) artificial neural networks (ANN), (5) generalized boosted regression trees (GBM), (6) random forests (RF), and (7) flexible discriminant analysis (FDA). For each species, we generated pseudo-absences using a random selection among the grid cells where the species was not reported, while maintaining a $50 \%$ prevalence [31].

Models were calibrated for the baseline (1950 - 2000) using an $80 \%$ random sample of the occurrence data, and model performance was assessed using the remaining $20 \%$. We evaluated model projections between observed and predicted distributions using area under the curve (AUC) of the receiver operating characteristic (ROC) [32], and the true skill statistic (TSS) [31]. Only species with AUC $>0.7$ [33] and TSS $>0.3$ have good prediction accuracy, and we found that no species had to be removed. Further, we used ensemble forecasting [34] to compute consensus projections for each species and scenario separately using the weighted average probability of occurrence per grid cell [35]; weights were based on the TSS obtained on the evaluation data. We then transformed the probability of occurrence for each species to presence-absence data by optimizing a threshold that maximizes the percentage of presence and absence correctly predicted for ROC curves [36]. We assessed the contribution of our dependent variables to predicting species ranges using the relative variable importance across all models [29]. The importance of each variable is calculated as 1 minus the correlation between the original prediction and a prediction made with a permuted variable; low correlations between the two predictions (i.e., high values) are indicative of highly influential variables.

To account for differences in species dispersal abilities, and to distinguish between areas with future suitable climatic conditions and areas with colonization potential, we incorporated dispersal data available from literature for each species, or for closely related species (i.e., maximum annual dispersal distances; Table S1). The annual dispersal values were then multiplied by 20 and respectively, 50 (i.e., years in the two time horizons) to obtain a maximum dispersal potential. Effective dispersal is influenced by the habitat matrix and potential barriers to movement (e.g., large bodies of water, high traffic highways, agricultural land, urban and rural areas, etc.), and habitat-specific vagility plays a large role in the successful dispersal of both amphibians [37] and reptiles [38]. Because the maximum annual dispersal distances do not account for such impacts, we also considered a more conservative scenario of no dispersal. Thus, for the two scenarios (with and without dispersal) we estimated potential distributional shifts as the difference between the number of grid cells currently occupied and the number predicted to be occupied under climate change (2020s and 2050 time horizons $\times 3$ emission scenarios) (Figure 1; Changes in species distributions).

\section{Conservation value analyses - irreplaceability and gap species}

We used irreplaceability analysis $[39,40]$ to evaluate the contribution of current Natura 2000 sites for reaching specific conservation targets defined for amphibians and reptiles, and to identify new priority areas for conservation. We conducted the irreplaceability analysis using C-Plan Systematic Conservation Planning System, version 4.1 [41], and binary (occupied/not occupied) species distribution projections, with and without dispersal under all climate change scenarios and time horizons. Irreplaceability of a PU is defined as its potential 


\section{Data used}

- Species occurrences

- Current climate data (WorldClim v.4)

- Future climate data (2020s and 2050s A1B, A2A, B2A; HadCM3)
- Landcover data (CORINE 2006)

- Species-specific dispersal data

- Natura 2000 (SCI) shape file

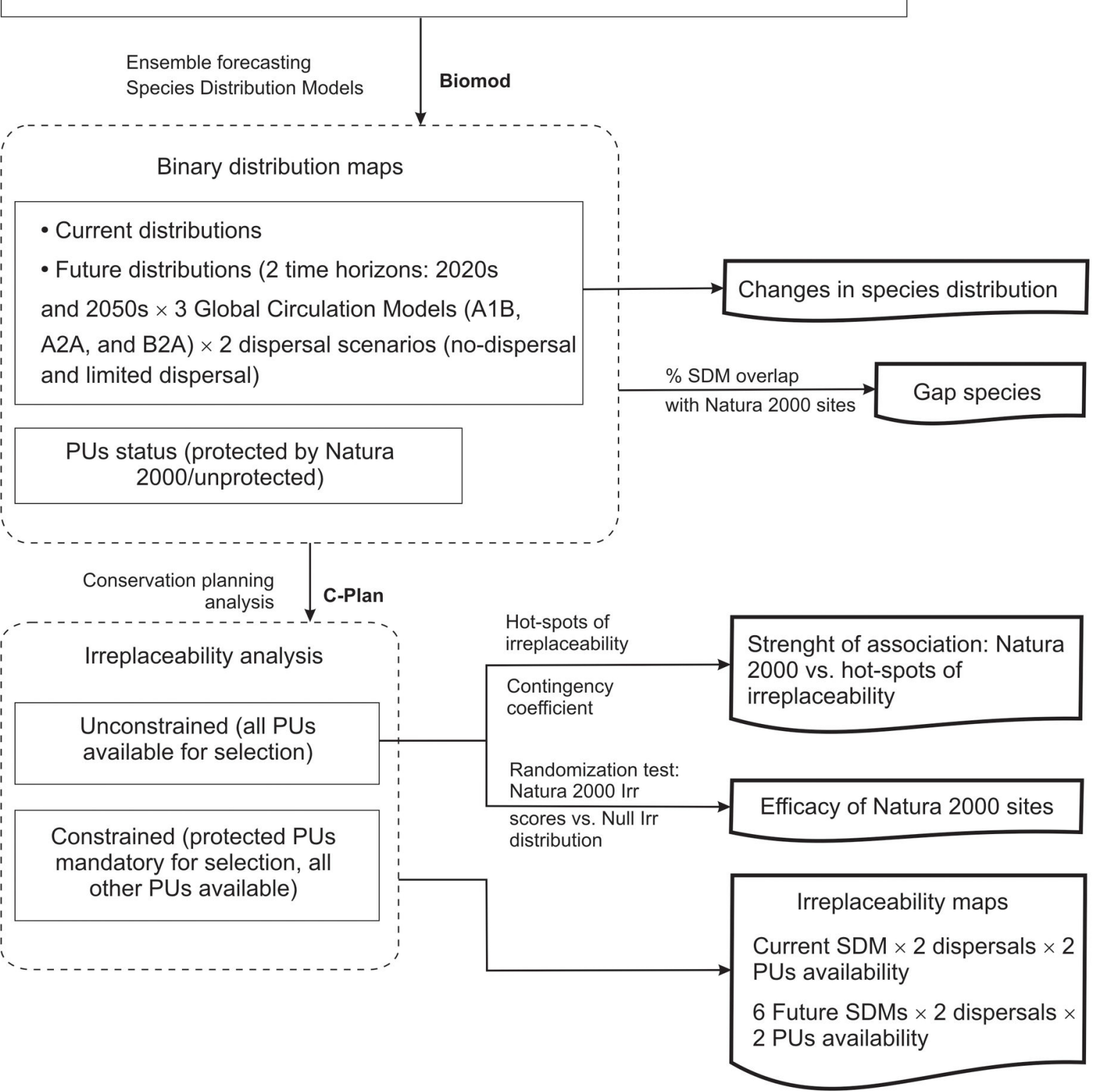

Figure 1. Flowchart of stages of analysis and data inputs. doi: 10.1371/journal.pone.0079330.g001

contribution to achieving specific conservation targets within a protected areas network [42]. The irreplaceability score reflects the importance of a PU for achieving the nation-wide conservation target [40]. We estimated the irreplaceability 
score for a given PUx, which is calculated by adding the irreplaceability scores for all species predicted to be present within PUx. Irreplaceability scores range between interval 0 and 1 , where values close to 1 identify planning units that are critical for achieving a given conservation target, and values close to 0 represent PUs easily replaceable sites, not contributing to conservation targets [39]. We ranked the irreplaceability scores into six classes: very low irreplaceability score $(\leq 0.2)$, low irreplaceability score $(0.2-0.4)$, moderate irreplaceability score $(0.4-0.6)$, high irreplaceability score $(0.6$ $-0.8)$, very high irreplaceability score $(0.8-<1)$, and completely irreplaceable (score $=1$ ).

Irreplaceability analysis requires defining specific conservation targets for each species. At European level, a species is considered to have excellent conservation status when $>60 \%$ of its range is included within Natura 2000 sites, and insufficient representation when $<20 \%$ of the range is protected. We decided to adopt a middle-ground representation threshold, and used a $40 \%$ target for each species. For each dispersal scenario (i.e. limited dispersal and no dispersal) and climate change projection we conducted irreplaceability analyses under two PU availability scenarios: (1) unconstrained (SCls and all other PUs available), and (2) constrained with SCls mandatory (i.e., irreplaceability score for $\mathrm{SCls}=1$, and all other PUs available). The first PU availability scenario was used to simulate a new protected area network, while the second scenario was used for identifying new highly irreplaceable areas to be added to the existing Natura 2000 network (Figure 1; Irreplaceability maps). For each dispersal scenario, we ran a total of 14 irreplaceability analyses: two for current distributions (2 PU availability scenarios), and 12 for future distributions ((3 GCM-2020s + 3 GCM-2050s) $\times 2$ PU availability scenarios).

Finally, we assessed the performance of the current Natura 2000 sites for reaching amphibian and reptile conservation targets by evaluating the percent range overlap with Natura 2000 sites (Figure 1; Gap species). Thus, species were classified as: (1) fully covered species ( $>40 \%$ of range is protected) (2), partial gap species ( $<40 \%$ of range is protected), and (3) gap species (no representation in protected areas).

\section{Natura 2000 effectiveness}

For each unconstrained time horizon, we tested the efficacy of SCls for conserving Romanian amphibian and reptile diversity using a randomization test under the null hypothesis that irreplaceability value of Natura 2000 sites is no different from that of a Null irreplaceability distribution [43] (Figure 1; Efficacy of Natura 2000 sites). The Null irreplaceability distributions were generated by using means of irreplaceability scores from 410 grid cells (i.e., equal to the number of protected PUs), drawn randomly from all the PUs pool regardless of their protection status; we repeated the procedure 1000 times for each scenario.

For the same unconstrained irreplaceability analysis, we performed a hot-spot analysis using the Getis-Ord Gi statistic to identify contiguous clusters of cells with irreplaceability values greater than expected [44] (Figure 1; Strength of association: Natura 2000 vs. hotspots or irreplaceability). The
Getis-Ord Gi statistic uses the local matrix of planning units (i.e., adjacent grid cells) to identify aggregations of high and low irreplaceability values by assigning Z-scores to each areal unit (Z-scores $>1.96$ denote significant hot spots of irreplaceability). We computed Getis-Ord Gi Z-scores in ArcGIS 10 (ESRI, Redlands, CA) using a threshold of $1.5 \mathrm{~km}$, in order to assess each PU in relation to its eight neighboring PUs.

We further evaluated the degree of overlap between protected PUs and irreplaceability hot-spots using the phi $(\varphi)$ contingency coefficient. Phi takes values between -1 and 1 , with values $\leq-0.7$ and $\geq 0.7$ indicating a strong association [45]. For each scenario, we built a matrix containing the following combinations: 1) protected PUs and irreplaceability hot-spots; 2) protected PUs and non-hot-spots; 3) unprotected PUs and hot-spots; 4) unprotected PUs and non-hot-spots. The weak correlations can be generated when: (1) the number of irreplaceability hot-spot grid cells is low, and (2) there is complete overlap between between hot-spots and protected PUs. Thus, we consider a significant degree of similarity between hot-spots and Natura 2000 sites, when: (1) $\varphi>0.3$ or (2) percent overlap $>50 \%$ [45].

\section{Results}

\section{Changes in species distributions}

The seven modeling techniques performed well for all species, and median AUC values ranged between 0.885 and 0.952 across models (Table S2). Random Forests provided the best predictive performance, with AUC $>0.95$ for 12 amphibian and 9 reptile species, followed by Generalized Boosted Regression Trees and Generalized Additive Models, while Classification Tree Analysis had the lowest performance. All models provided similar performance for both amphibians and reptiles (Mann-Whitney tests for model-specific averaged cross-validated AUC, p-values >0.25).

The contribution of variables to predicting species distributions ranged widely across species and modeling techniques (Figure 2). Overall, the land cover variables had a lower contribution to predicting current ranges compared to bioclimatic variables; the percent agricultural lands within the $100 \mathrm{~km}^{2}$ grid cells ranked highest among the land cover variables (median relative importance $=0.03$ for both taxa). The best predictors for reptile distributions were the annual precipitation $(0.20)$, the mean temperature of the warmest quarter (0.18), and mean annual temperature (0.19). For amphibians, the best predictors were mean annual temperature (0.27), and the precipitation of the warmest quarter (0.17).

The distributions of both amphibians and reptiles based on consensus predictions showed a diverse response to climate change across all emission and dispersal scenarios (Table 1). Under the no-dispersal scenario, the majority of the species (31 species for $\mathrm{A} 1 \mathrm{~B}$ and 32 species for $\mathrm{A} 2 \mathrm{~A}$ and $\mathrm{B} 2 \mathrm{~A}$ ) lose suitable climate space by 2020 s (i.e., 'loser' species) (median loss = $45.1 \%$ across all emission scenarios), with Rana arvalis being most affected (>90\% reduction under all emission scenarios; Table 1). Testudo hermanni is predicted to completely lose climate space under the A2A and B2A scenarios. The 2050s time horizon shows a further reduction of suitable climate 


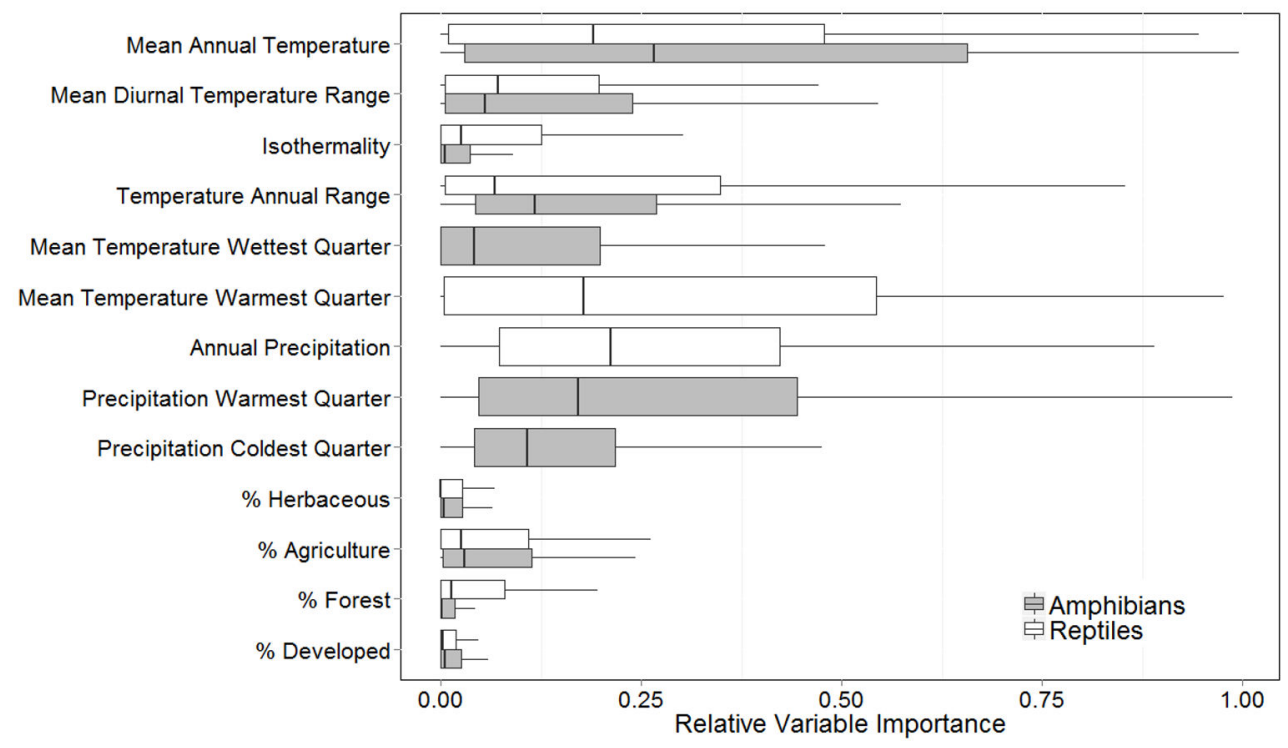

Figure 2. Box-and-whisker plot of relative importance of variables used to model amphibian and reptile distributions; computation of relative variable importance is described in the Methods section.

doi: 10.1371/journal.pone.0079330.g002

space for most species (median loss $=58.2 \%$ ), and Anguis fragilis, $R$. arvalis and $R$. lessonae are predicted to completely lose suitable climate space.

Under the limited dispersal scenario, the median range loss is lower for both 2020 s ( $40.1 \%$ across all emission scenarios), and 2050s (49.4\%), but the magnitude and direction of change varies by species and emission scenario (Table 1). Among 'winner' species, one amphibian (Pelobates syriacus) and eight reptile species (Coluber caspius, Elaphe quatuorlineata, Eremias arguta, Lacerta praticola [A1B only], L. trilineata, Podarcis taurica, Testudo graeca, and Vipera ammodytes [A1B only]) are predicted to gain suitable climate space for both 2020s and 2050s. Despite allowing for potential dispersal, severe reductions in the number of cells occupied $(>90 \%)$ are predicted for some 2050s emission scenarios for Bufo bufo, Triturus vulgaris, Coronella austriaca, Elaphe longissima, and Podarcis muralis (Table 1). In addition, predictions of complete loss of suitable climate space are consistent with the no-dispersal scenario for both 2020 s and 2050s.

For both dispersal scenarios, range loses were highest under emission scenario B2A for 2020s, and A1B for 2050s (Table 1), but within each time horizon the differences there were not significant (asymptotic 3-sample permutation test; $p$-values $>0.3$ ). Across all emission scenarios, reptiles are predicted to lose suitable climate space at a slower pace compared to amphibians (Table 1), with the highest differences manifesting under the 2050s limited dispersal scenario (asymptotic 2sample permutation test; $p$-value $=0.042$ ).

\section{Gap species}

Under current conditions all 37 reptile and amphibian species are represented at some degree in SCls. Of these, 35 species (21 reptiles and 14 amphibians) are gap species ( $<40 \%$ of their current distribution in SCls; Figure 3, Table S3, Table S4). Among the gap species, 12 species have $<20 \%$ of their distribution in protected areas, with Rana arvalis $(8.67 \%$; species at its southern distribution limit) and Bombina bombina (10.23\%; lowland species). The only two species that reach the $40 \%$ target are Eremias arguta (81.35\%) and Vipera ursinii $(62.5 \%)$; both species have very small and fragmented ranges overlapping with Natura 2000 sites.

For the 2020 and 2050 time horizons, the number of species that meet the $40 \%$ target increases (target met for $4-14$ species depending on dispersal, time horizon and emission scenario; Figure 3, Table S3, Table S4). Concomitantly, the number of species that are marginally represented or are completely absent from SCls increases. For example, Testudo hermanni completely loses suitable climate space under several emission scenarios, and Rana arvalis becomes either marginally protected or not represented in SCls for all 2020 scenarios. Species such as Triturus montandoni, Rana lessonae, Eremias arguta and Vipera ursinii are predicted to be $100 \%$ represented in the current SCIs. In 2050, the number of marginally represented species increases, with Coronella austriaca, Anguis fragilis, Testudo hermanni, Rana lessonae, and Triturus vulgaris being most impacted.

\section{Irreplaceability analysis}

Current conditions. Currently, 92\% of PUs (unconstrained availability) and $96 \%$ of PUs (constrained availability) have low and very low irreplaceability values $(\leq 0.4)$. The remaining PUs under each scenario have moderate irreplaceability scores $(0.4$ - 0.6). Under the unconstrained availability scenario, $51 \%$ of PUs with moderate irreplaceability $(\mathrm{N}=192)$ occur in SE Romania (Steppic and Black Sea BGRs), and 39\% in SW and W Romania (Continental BGR), as well as the Alpine BGR 
Table 1. Current range extent (number of occupied $10 \times 10 \mathrm{~km}$ grid cells) and percent range change under future climate conditions (2020s and 2050s time horizons, emission scenarios A1B, A2A, and B2A) and dispersal assumptions, predicted using ensemble species distribution models; negative values denote range contractions (LimD = limited dispersal; NoD $=$ no dispersal).

\begin{tabular}{|c|c|c|c|c|c|c|c|c|c|c|c|c|c|}
\hline \multirow[t]{2}{*}{ Species } & \multirow[t]{2}{*}{ Current range } & \multicolumn{2}{|c|}{ A1B2020s } & \multicolumn{2}{|c|}{ A2A2020s } & \multicolumn{2}{|c|}{ B2A20202s } & \multicolumn{2}{|c|}{ A1B2050s } & \multicolumn{2}{|c|}{ A2A2050s } & \multicolumn{2}{|c|}{ B2A2050s } \\
\hline & & NoD & LimD & NoD & $\operatorname{Lim} D$ & NoD & LimD & NoD & LimD & NoD & LimD & NoD & $\operatorname{Lim} D$ \\
\hline \multicolumn{14}{|l|}{ AMPHIBIANS } \\
\hline Salamandra salamandra & 1190 & -36.5 & -36.5 & -48.2 & -48.2 & -40.8 & -40.3 & -36.8 & -36.7 & -32.8 & -32.3 & -25.5 & -24.0 \\
\hline Triturus alpestris & 737 & -19.5 & -19.0 & -25.6 & -25.4 & -28.5 & -28.5 & -30.5 & -30.4 & -35.1 & -35.1 & -35.3 & -35.3 \\
\hline Triturus cristatus & 1448 & -44.5 & -40.7 & -41.6 & -37.1 & -60.2 & -56.2 & -84.6 & -78.7 & -79.6 & -74.6 & -84.5 & -81.4 \\
\hline Triturus dobrogicus & 244 & -80.3 & -80.3 & -82.0 & -82.0 & -83.6 & -83.6 & -84.4 & -84.4 & -87.3 & -87.3 & -86.5 & -86.5 \\
\hline Triturus montandoni & 498 & -28.1 & -26.9 & -17.1 & -14.9 & -39.4 & -36.1 & -61.4 & -54.8 & -53.6 & -36.7 & -47.0 & -25.9 \\
\hline Triturus vulgaris & 1425 & -45.1 & -40.1 & -56.6 & -54.7 & -77.0 & -74.9 & -94.3 & -93.0 & -93.7 & -92.8 & -98.2 & -98.0 \\
\hline Bombina bombina & 1184 & -19.6 & -12.1 & -20.7 & -14.9 & -26.4 & -19.8 & -27.9 & -18.8 & -26.4 & -11.7 & -25.7 & -7.9 \\
\hline Bombina variegata & 1392 & -37.1 & -37.1 & -44.7 & -44.7 & -60.3 & -60.3 & -82.8 & -82.8 & -83.3 & -83.3 & -84.7 & -84.7 \\
\hline Pelobates fuscus & 641 & -32.4 & -26.1 & -32.6 & -27.0 & -39.9 & -36.2 & -41.2 & -32.4 & -42.3 & -34.9 & -42.9 & -31.5 \\
\hline Pelobates syriacus & 119 & 0.0 & 63.0 & -0.8 & 43.7 & 0.0 & 64.7 & 0.0 & 222.7 & 0.0 & 222.7 & 0.0 & 222.7 \\
\hline Bufo bufo & 1342 & -54.5 & -52.8 & -71.2 & -69.7 & -78.1 & -77.5 & -90.5 & -90.3 & -94.2 & -94.1 & -92.1 & -91.9 \\
\hline Bufo viridis & 1564 & -30.2 & -13.5 & -50.6 & -40.3 & -39.8 & -20.5 & -44.8 & -17.7 & -41.1 & -5.9 & -22.1 & 25.8 \\
\hline Hyla arborea & 1454 & -39.8 & -24.4 & -46.4 & -33.1 & -66.2 & -57.8 & -71.7 & -62.6 & -67.1 & -55.9 & -46.1 & -27.2 \\
\hline Rana arvalis & 465 & -94.2 & -94.0 & -98.5 & -98.5 & -99.6 & -99.6 & -100.0 & -100.0 & -100.0 & -100.0 & -100.0 & -99.8 \\
\hline Rana lessonae & 235 & -85.5 & -85.5 & -80.9 & -80.9 & -98.7 & -98.7 & -99.6 & -99.6 & -99.6 & -99.6 & -100.0 & -100.0 \\
\hline Rana temporaria & 1269 & -56.7 & -56.7 & -60.8 & -60.8 & -76.5 & -76.5 & -90.2 & -90.2 & -92.6 & -92.6 & -93.2 & -93.2 \\
\hline \multicolumn{14}{|l|}{ REPTILES } \\
\hline Emys orbicularis & 801 & -46.7 & -34.2 & -58.2 & -48.4 & -56.6 & -44.7 & -67.4 & -51.2 & -68.7 & -57.3 & -66.2 & -57.4 \\
\hline Testudo graeca & 194 & 0.0 & 43.3 & -2.1 & 39.2 & 0.0 & 45.4 & 0.0 & 134.5 & 0.0 & 105.2 & 0.0 & 85.6 \\
\hline Testudo hermanni & 111 & -34.2 & -14.4 & -100.0 & -100.0 & -100.0 & -100.0 & -90.1 & -89.2 & -100.0 & -100.0 & -100.0 & -100.0 \\
\hline Anguis fragilis & 1167 & -66.5 & -66.5 & -75.1 & -75.1 & -77.6 & -77.6 & -100.0 & -100.0 & -100.0 & -100.0 & -99.9 & -99.9 \\
\hline Eremias arguta & 59 & 0.0 & 27.1 & 0.0 & 28.8 & 0.0 & 28.8 & 0.0 & 127.1 & 0.0 & 105.1 & 0.0 & 64.4 \\
\hline Lacerta agilis & 1643 & -57.3 & -57.2 & -53.7 & -52.6 & -66.6 & -65.2 & -91.2 & -91.1 & -87.9 & -87.3 & -84.5 & -83.8 \\
\hline Lacerta praticola & 160 & -16.9 & 23.8 & -52.5 & -40.0 & -57.5 & -45.6 & -18.1 & 92.5 & -28.8 & 63.8 & -28.1 & 65.0 \\
\hline Lacerta trilineata & 170 & 0.0 & 35.3 & 0.0 & 34.7 & 0.0 & 35.3 & 0.0 & 89.4 & 0.0 & 90.0 & 0.0 & 91.8 \\
\hline Lacerta viridis & 1352 & -12.6 & 0.1 & -26.4 & -13.5 & -26.4 & -13.6 & -18.2 & 12.4 & -25.6 & 2.3 & -28.5 & -5.5 \\
\hline Podarcis muralis & 714 & -50.1 & -44.3 & -94.5 & -94.5 & -89.5 & -89.5 & -81.6 & -79.3 & -97.9 & -97.9 & -95.0 & -95.0 \\
\hline Podarcis taurica & 516 & 0.0 & 28.1 & 0.0 & 28.7 & 0.0 & 29.1 & 0.0 & 85.3 & 0.0 & 86.2 & 0.0 & 85.5 \\
\hline Lacerta vivipara & 803 & -41.3 & -41.3 & -33.6 & -32.4 & -39.4 & -38.7 & -68.1 & -68.1 & -58.2 & -58.2 & -53.2 & -53.2 \\
\hline Ablepharus kitaibelii & 173 & -36.4 & -15.6 & -45.7 & -37.0 & -50.9 & -41.6 & -36.4 & 16.8 & -45.7 & -7.5 & -50.9 & -13.9 \\
\hline Coronella austriaca & 822 & -73.6 & -73.4 & -89.4 & -89.4 & -90.6 & -90.6 & -99.5 & -99.5 & -99.9 & -99.9 & -99.4 & -99.4 \\
\hline Elaphe longissima & 762 & -74.9 & -73.6 & -95.1 & -94.8 & -92.7 & -92.1 & -95.0 & -85.7 & -97.1 & -95.7 & -97.2 & -96.2 \\
\hline Coluber caspius & 207 & -9.7 & 11.1 & -18.4 & -2.4 & -18.8 & -1.4 & -21.2 & 63.8 & -21.3 & 40.6 & -21.3 & 38.2 \\
\hline Elaphe quatuorlineata & 83 & 0.0 & 109.6 & 0.0 & 122.9 & 0.0 & 122.9 & 0.0 & 373.5 & 0.0 & 301.2 & 0.0 & 233.7 \\
\hline Natrix tessellata & 848 & -72.9 & -65.4 & -87.1 & -79.1 & -89.2 & -82.7 & -86.5 & -80.1 & -89.5 & -87.9 & -90.3 & -88.6 \\
\hline Vipera ammodytes & 289 & -27.3 & 3.5 & -64.0 & -58.1 & -64.7 & -55.4 & -33.5 & 88.9 & -55.4 & -15.6 & -56.7 & -32.9 \\
\hline Vipera berus & 992 & -52.3 & -52.0 & -53.8 & -53.2 & -61.6 & -61.5 & -88.0 & -88.0 & -83.6 & -83.6 & -78.4 & -78.4 \\
\hline Vipera ursinii & 49 & -32.7 & -20.4 & -32.7 & -20.4 & -34.7 & -24.5 & -34.7 & -22.4 & -34.7 & -20.4 & -34.7 & -20.4 \\
\hline
\end{tabular}

doi: 10.1371 /journal.pone.0079330.t001

(Figure 4), suggesting that conservation actions should focus on these regions regardless of their protection status. When the existing SCls are considered irreplaceable, additional priority areas that currently do not benefit of protection occur mostly in NW Romania in two BGRs: Continental (N = 50 PUs), and Pannonian ( $\mathrm{N}=31 \mathrm{PUs}$; Figure 4).

Future conditions. Under the unconstrained irreplaceability scenario, high and very high irreplaceability PUs (score $>0.6$ ) are predicted under all emission and dispersal scenarios
(Figure S1). The Steppic-Black Sea, and Alpine BGRs have the highest irreplaceability values, regardless of emission and dispersal scenarios, with up to $154 \mathrm{PUs}(6 \%)$ in categories high and very high in 2020s (B2A, no-dispersal), and up to 206 PUs (8\%) in 2050s (A1A, no-dispersal) (Figure 5, Figure S2).

When existing $\mathrm{SCls}$ are considered irreplaceable (constrained availability scenario), $>95 \%$ of PUs have moderate and lower irreplaceability scores $(<0.6)$ under all emission and dispersal scenarios (Figure S1). Similar to the 

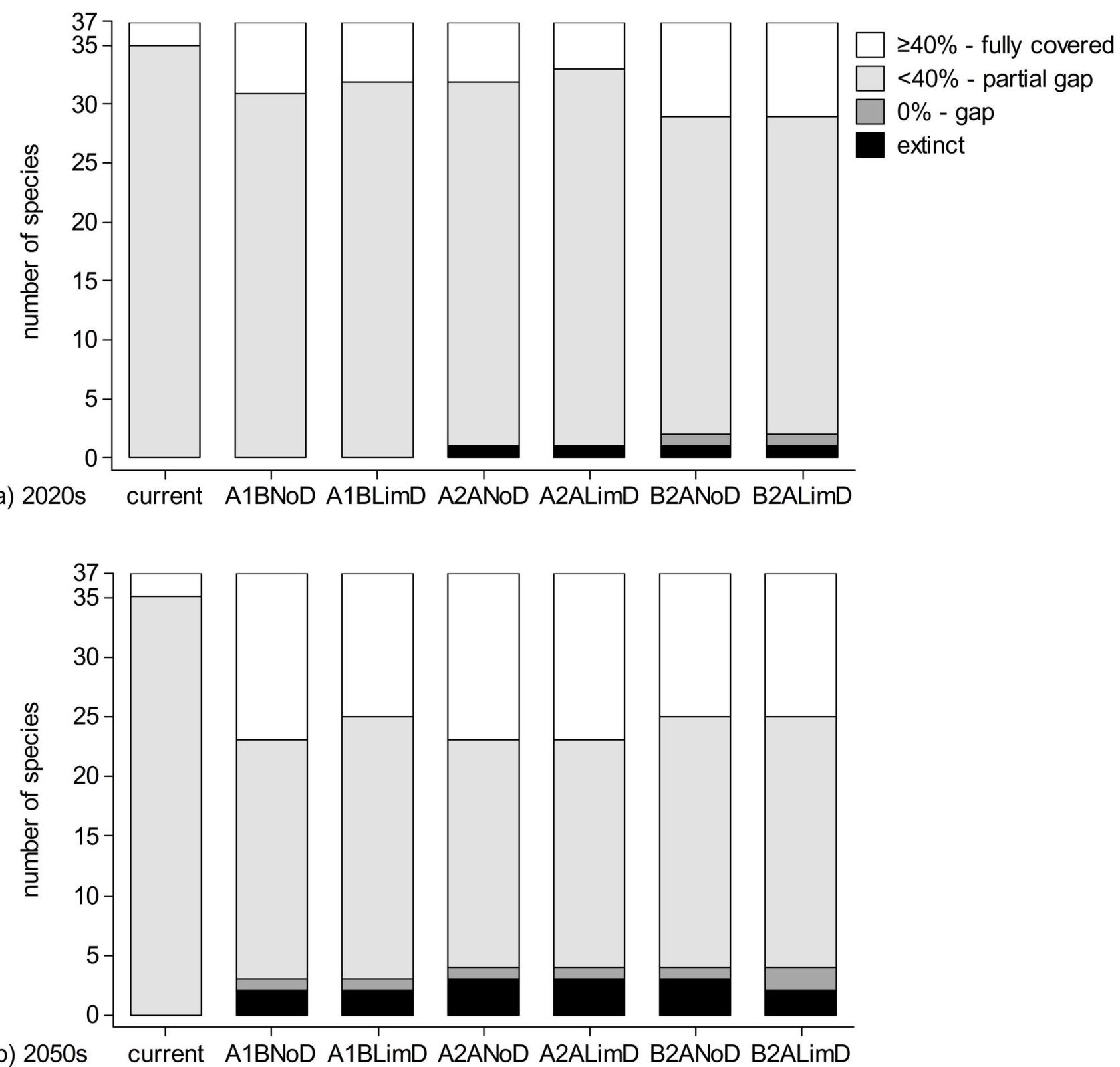

Figure 3. Representation of amphibian and reptile species in Romanian Natura 2000 sites under current and future climate conditions for limited- and no-dispersal scenarios (shown as percentage of planning units of species ranges in Sites of Community Importance).

doi: 10.1371/journal.pone.0079330.g003

current conditions, the Steppic-Black Sea BGRs have the highest priority highlighting the need to complementary protection in SE Romania. In addition, moderately valuable areas for herpetofauna conservation are predicted in SW and W Romania (e.g., B2A, no-dispersal) (Figure 5, Figure S2).

\section{Efficacy of Natura 2000}

Natura 2000 sites have higher irreplaceability scores compared to a set of randomly sampled PUs under both the current climate and future climates for all emission and dispersal scenarios, suggesting that the current protected areas network is critical for achieving conservation targets for Romanian reptiles and amphibians (Table S5). However, we found a weak spatial association between protected areas (SCls) and irreplaceability hotspots $(\varphi<0.33)$ under both current and future conditions (Table 2). Current conditions had the weakest association, with $45.4 \%$ of SCls overlapping irreplaceability hotspots, and $\varphi=0.14$. In 2020s, the strength of the association increases up to 0.32 and $57.8 \%$ overlap (A2A, no-dispersal). In 2050 s the spatial overlap recorded values 

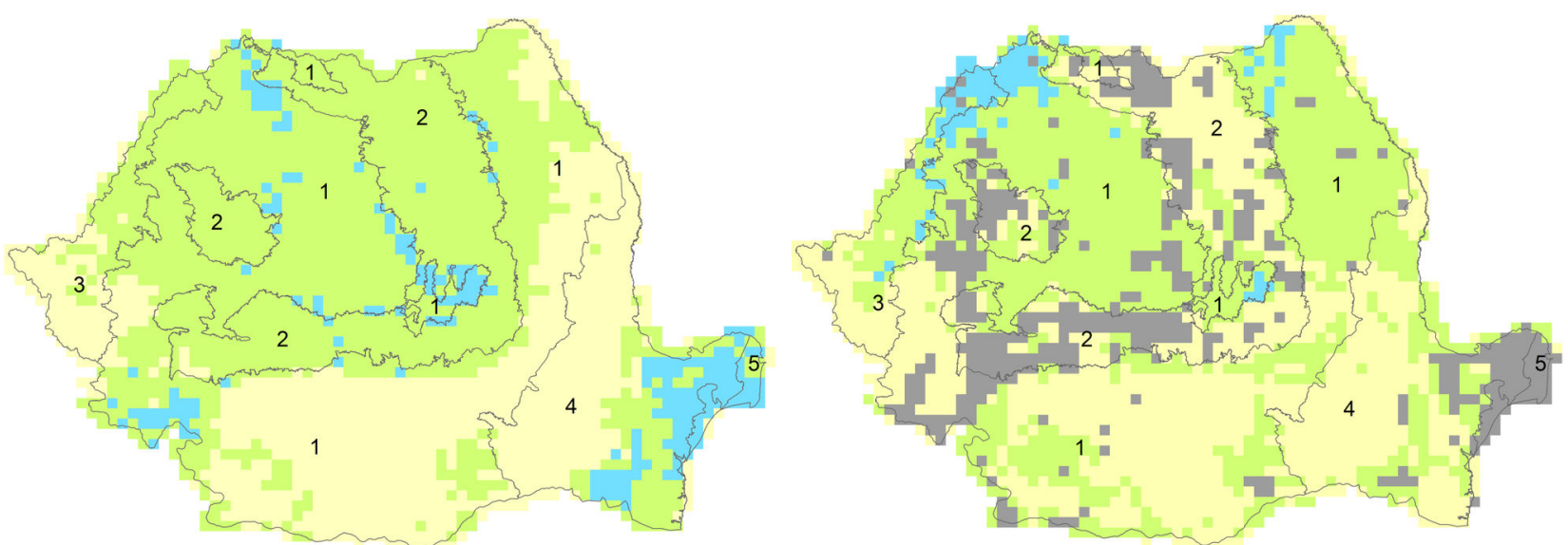

1 - Continental BGR; 2 - Alpine BGR; 3 - Pannonian BGR; 4 - Steppic BGR; 5 - Black Sea BGR irreplaceability scores

$\leq 0.2 \quad 0.2-0.4 \square|0.4-0.6 \square| 0.6-0.8 \square 0.8-<1 \square 1 \square$ Natura 2000 sites

Figure 4. Planning unit (PU) irreplaceability scores under (a) unconstrained PU availability scenario (all PUs available for selection), and (b) constrained PU availability scenario (all currently protected PUs are given a score of 1 ). For (a), areas in blue represent priority areas for reptile and amphibian conservation regardless of their protection status. When all current SCls are considered highly irreplaceable (b), northwest Romania becomes a conservation priority.

doi: 10.1371/journal.pone.0079330.g004

similar to 2020 s scenario ( $\varphi<0.33$ and $46.59 \%$ overlap (A2A, no-dispersal, Table 2).

\section{Discussion}

Our study showed that the forecasted climate changes will trigger important shifts of species ranges, with most species suffering range contractions ('loser' species), while a few will benefit ('winner' species). Under current conditions, the existing network of SCls does not perform well for conserving the reptile and amphibian fauna, and we identified new priority areas for conservation. In contrast to other studies (e.g., [46]), we found that under future climate conditions, the existing protected areas network is likely to increase the representation of the Romanian reptile and amphibian fauna, owing to the interaction between drastic range contractions, and range shifts towards currently protected areas.

We used a biogeographic region approach to evaluate conservation priorities, and identified two core BGRs as critical to maintaining amphibian and reptile diversity: the Alpine and Steppic-Black Sea BGRs (Figure 4). These findings have important conservation implications. They suggest that despite known shortcomings of the Natura 2000 ecological network (e.g., uneven representation of European biogeographic regions, lack of connectivity, etc.; [16-18]), focusing conservation efforts on the existing $\mathrm{SCls}$ (e.g., by improving their institutional capacity) is likely to improve the conservation status of herpetofauna in the future. We also recommend establishing new SCls or incentivizing conservation actions in the priority areas outside protected lands would lead to better conservation status in the future.

\section{Predicted range changes - 'loser' and 'winner' species}

There are differences in the responses of the two taxa, with amphibians unequivocally constricting their ranges during 2020s and 2050s, and reptiles showing mixed responses to climate change. Specifically, when considering limited dispersal, most amphibians are predicted to be 'loser' species, while among reptiles there are both 'loser' and 'winner' species (see Table 1). Such responses corroborate previous findings in Europe, which suggest that moisture and precipitation would become a limiting factor for amphibians, while climate warming might allow several reptile species to expand their ranges [15,46-48].

One of the interesting findings of our study was that $T$. hermanni, $A$. fragilis, $R$. arvalis and $R$. lessonae are predicted to completely lose climate space by 2050 s under all emission scenarios (Table 1). This does not mean that species will completely disappear within a relatively short period of time (e.g., 2 generations for T. hermanni), but it is rather indicative of the fact that novel climates are likely to occur within these species' current ranges. This raises an important ecological question: how will animals cope with novel climates which may have no analogues under current conditions [49,50]. The thermal tolerance breadth of ecotherms is greater in temperate latitudes of the Northern Hemisphere, compared to tropical latitudes [51,52]. This suggests that species whose distributions are highly influenced by temperature, such as reptiles, may persist in novel climates, despite our predictions 
unconstrained scenarios

A2A LimD 2020s

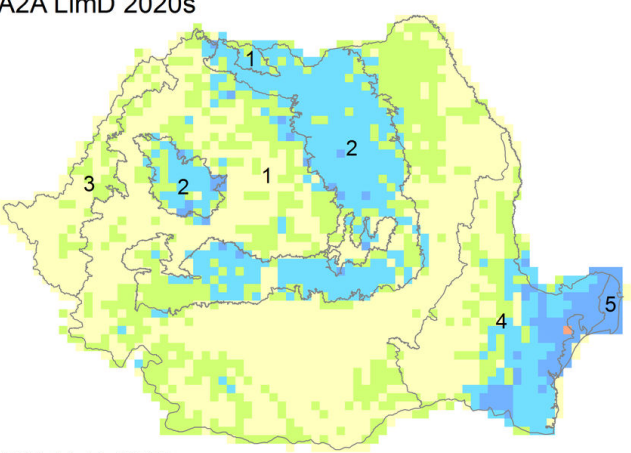

A2A NoD 2020s

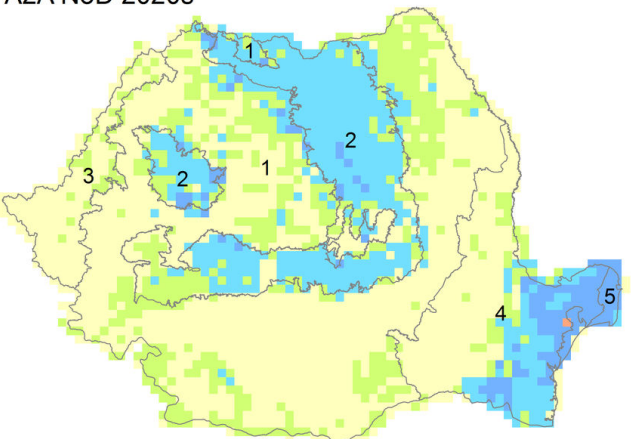

A2A LimD 2050s

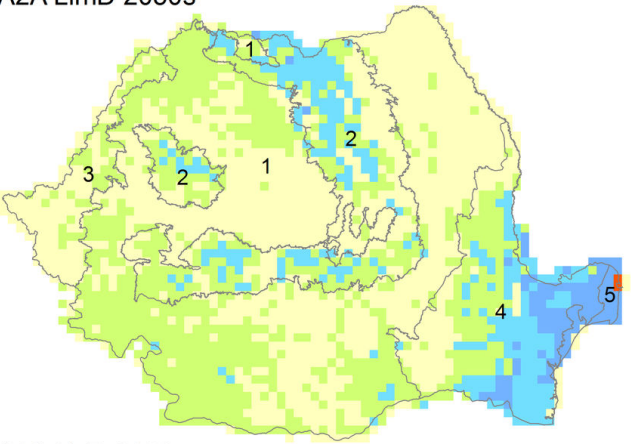

A2A NoD 2050s

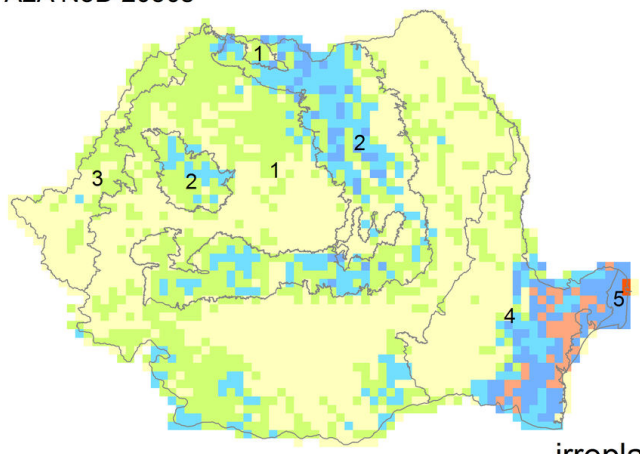

constrained scenarios

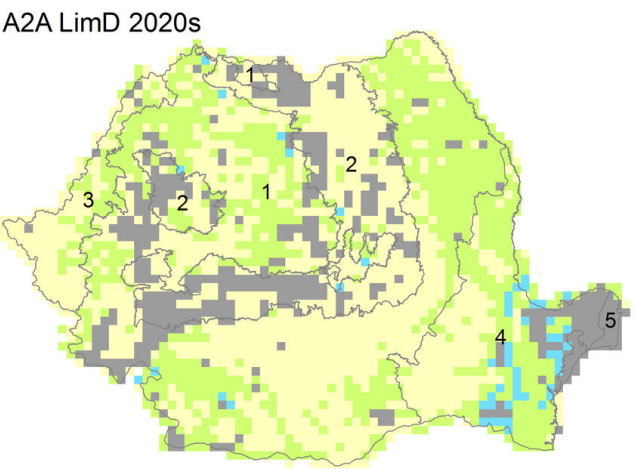

A2A NoD 2020s

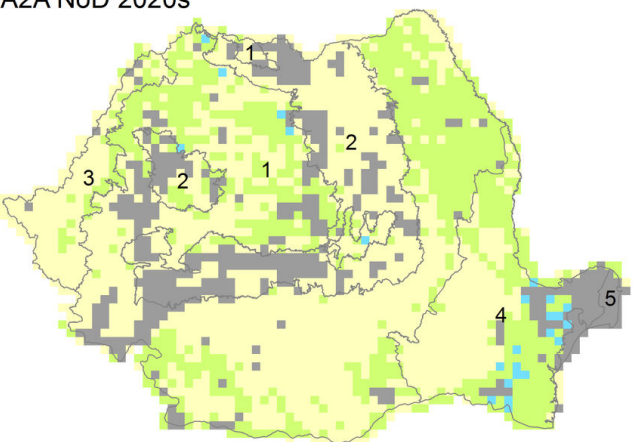

A2A LimD 2050s

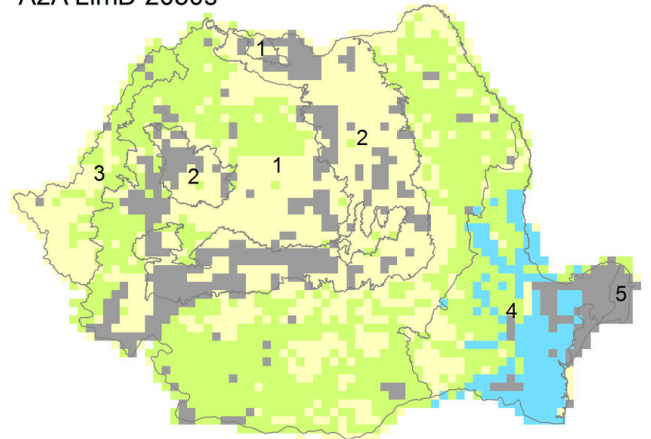

A2A NoD 2050s

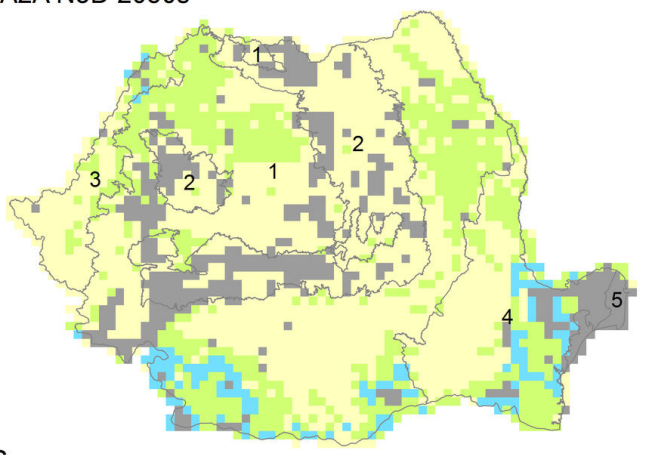

$\leq 0.2$

$0.2-0.4$

$0.4-0.6$

replaceability scores

1 - Continental BGR; 2 - Alpine BGR; 3 - Pannonian BGR; 4 - Steppic BGR; 5 - Black Sea BGR

Figure 5. Example future irreplaceability scores (emission scenario A2A) under constrained (left panels) and unconstrained (right panels) planning unit availability for the 2020 s and 2050 s time horizons and three emission scenarios, under limited (LimD) and no dispersal (NoD) assumptions.

doi: 10.1371/journal.pone.0079330.g005 
Table 2. Strength of association (coefficient of correlation $\phi$ ) and percent overlap between hot-spots of irreplaceability and Natura 2000 planning units under current and future climate conditions (2020s and 2050, three emission scenarios) under limited dispersal (LimD) and no dispersal (NoD) assumptions.

\begin{tabular}{llllll}
\hline Climate scenario & $\boldsymbol{\phi}$ & $\mathbf{x}^{2}$ value & p-value & \% overlap \\
\hline Current & & 0.14 & 49.94 & $<0.001$ & 45.37 \\
A1B2020s & NoD & 0.32 & 260.92 & $<0.001$ & 57.80 \\
& LimD & 0.31 & 244.86 & $<0.001$ & 57.07 \\
A2A2020s & NoD & 0.28 & 199.76 & $<0.001$ & 52.20 \\
& LimD & 0.28 & 199.76 & $<0.001$ & 51.71 \\
B2A2020s & NoD & 0.30 & 229.32 & $<0.001$ & 50.73 \\
& LimD & 0.28 & 199.76 & $<0.001$ & 49.76 \\
A1B2050s & NoD & 0.33 & 277.48 & $<0.001$ & 46.59 \\
& LimD & 0.23 & 134.79 & $<0.001$ & 39.02 \\
A2A2050s & NoD & 0.31 & 244.86 & $<0.001$ & 44.88 \\
& LimD & 0.23 & 134.79 & $<0.001$ & 37.07 \\
B2A2050s & NoD & 0.32 & 260.92 & $<0.001$ & 45.37 \\
& LimD & 0.29 & 214.29 & $<0.001$ & 42.20 \\
\hline
\end{tabular}

doi: 10.1371 /journal.pone.0079330.t002

of complete climate space loss. However, the responses to novel climates are unknown, and these findings suggest that niche-based species distribution models need to be revisited, by incorporating other sources of uncertainty, or rely on mechanistic relations between species and their environment [5]. In addition, there is limited evidence that anthropogenic climate change alone is responsible for species extinctions (e.g., through changes in temperature and moisture regimes which directly affect physiological tolerances), and that species interactions and food availability better correlate with extinction risk [53]. Another source of uncertainty is represented by the potential for evolutionary rescue (i.e., rapid adaptive responses to novel conditions), either through phenotypic plasticity $[54,55]$ or genetic change [56]. For example, incorporating adaptation along with migration potential for predicting responses of 48 tree species in British Columbia to climate change, predicted the persistence of a higher number of tree populations compared to no-adaptation scenarios [7]. While the time horizon for our predictions is relatively narrow when considering evolutionary time scales, the short generation time and known plasticity of many amphibian and reptile species could potentially allow for evolutionary rescue. In addition, local adaptation would lead to different responses of populations across a species range, further adding to the uncertainty in predicting climate change impacts [57].

\section{Priority areas for herpetofauna conservation}

Under the unconstrained irreplaceability scenario (i.e., regardless of existing protection status), both current and future conditions, the Alpine BGR (Carpathian Mountains) and the Steppic-Black Sea BGRs (SE Romania) have the highest priority for conservation of Romanian reptiles and amphibians (Figure 4, Figure 5, Figure S2). Agreement across multiple emission and dispersal scenarios and time horizons suggest that current and future conservation strategies should focus on these regions [20].

Our finding on the Alpine BRG as a high conservation priority area corroborates the results of continental-level studies $[15,20]$, which also suggest that the Carpathians (especially Southern Carpathians) represent a top priority for European reptiles and amphibians. Such agreement between national and European level targets emphasizes the importance of the Romanian Alpine BGR to the conservation of European herpetofauna, while providing national-level priorities. The Carpathians host the majority of Romania's forest ecosystems, and the resilience of the Alpine BGR to climate change is dependent on maintaining healthy forest ecosystems, and incorporating uncertainty into forest management strategies [58]. However, such issues gained little or no attention in Romania, and the most notable land use changes are taking place in the Carpathians. Deforestation represents the main driver of change, and rapid forest cover losses occurred in the post-socialist era through uncontrolled clear-cutting practices, which do not emulate the natural disturbance regimes [59]. Notably, such disturbances have been affecting, and continue to affect protected areas [60]. High rates of logging within and outside protected areas are the direct result of changes in land ownership in the post-socialist period [60], but also of weak regulatory, institutional, and enforcement potential of newly created protected areas [17]. Thus, in many parts of the Carpathians, forest cover has been reduced to fragments [61], which could affect the resilience of these ecosystems to climate change. Specifically for forest amphibians, which require both terrestrial and aquatic habitats during their complex lifecycles, there are no forest practices regulations that protect aquatic ecosystem integrity [62].

One of the findings of our study is identifying SE Romania (Dobrogea) as a priority area for herpetofauna conservation under both current and future climate scenarios (Figure 4, Figure 5, Figure S2). Due to its distinct location within three geographic barriers (Danube River at W and N, and Black Sea at E) Dobrogea is physically and functionally connected to the Balkan Peninsula, and has a unique herpetofauna ( $T$. graeca, Pelobates syriacus, Eremias arguta, Lacerta trilineata, Elaphe quatuorlineata have the core range in SE Romania [22]), and high irreplaceability values. Abandonment of agricultural land is another common driver of land use change in post-socialist Romania [63], with large areas afforested and/or converted to natural vegetation [64]. Dobrogea is a region where cropland abandonment has been severe, and was concomitantly affected by droughts, soil erosion and desertification [65]. Decreased agricultural use and associated use of pesticides, and conversion to natural vegetation are likely to increase the likelihood that Dobrogea will remain a stronghold for Romanian herpetofauna in the future. In addition, focusing on abandoned croplands could reduce the likelihood for potential conflicts between conservation targets and economic interests of local communities.

However, partial mismatches between European level and national level predictions of top priority areas for conservation raise additional questions on how do national priorities play out 
in the overall vision for building a coherent Natura 2000 network $[18,19,24]$.

\section{Efficacy of the Natura 2000 network for protecting amphibians and reptiles}

The current Natura 2000 network does not meet European conservation targets for the majority of Romanian reptiles $(\mathrm{N}=19)$ and amphibians $(\mathrm{N}=16)$, yet many amphibians and reptiles are predicted to have higher levels of representation of under future emission scenarios. Shrinking distributions due to climate change can occasionally lead to increases in species representation in Natura 2000 network if the remaining ranges overlap with protected areas, potentially explaining why species such as Triturus montandoni, Eremias arguta or Vipera ursinii are predicted to become fully represented species in the future scenarios (Table S3, Table S4). At the same time, several other species (some of which are predicted to completely lose climate space) fail to be represented in the current ecological network (Table S3, Table S4). The findings on the performance of existing $\mathrm{SCls}$ are not surprising, and they corroborate previous findings on the overall efficacy of the Romanian protected areas network. Using species inventories from existing SCls [17], found that the majority of reptiles and amphibians were represented in at least one $\mathrm{SCl}$, and that their overall protection level was inadequate. While representation in protected areas might be a good proxy for assessing a species conservation status, coverage alone does not warrant protection. In Romania, the total protected area increased from $4.1 \%$ to $22.7 \%$ of the national territory between 1990 and 2013 , but it was not matched by an increase in efficacy of meeting conservation targets [17]. The result was an overrepresentation of undeveloped, yet potentially important resource extraction areas (mountains, floodplains, and Danube Delta), and under-representation of highly impacted areas, where immediate conservation measures are most needed $[17,59]$. As such, there are regional differences which highlight the under-representation of several BGRs in the current protected areas network. The Alpine BGR is best represented (47.8\% of all Romanian SCls), thus forest species and those associated with higher elevations benefit of the best protection. Species whose distributions are limited to Pannonian, Continental, and Steppic BGRs, located in NW, SW, and SE Romania, respectively tend to be under-represented.

The strength of association and spatial overlap between the Natura 2000 network and the irreplaceability hotspots increases under future climate projections, compared to current conditions (Table 2). This suggests that existing SCls are critical for achieving future conservation targets for Romanian herpetofauna. Because no prior consideration was given to spatial planning under climate change scenarios [19], this finding can be explained by the fact that the Alpine and Steppic-Black Sea BGRs contain the bulk of Natura 2000 sites, and represent climate refugia for many amphibian and reptile species.

Despite higher representation of amphibians and reptiles in protected areas under future conditions, approximately $75 \%$ (2020s scenarios) and 50\% (2050s) of the species are still gap species (Figure 3). Within the two under-represented BGRs (i.e., Pannonian and Continental), conservation of reptiles and amphibians could be strengthened by establishing new SCls, but also by promoting conservation strategies that make the local people an integral part of the solution [66,67]. For example, traditionally-managed areas in Romania are already recognized as important landscapes for reptile and amphibian conservation (e.g., $[62,68])$. Thus, an important next step would be to evaluate the overlap between these landscapes and future irreplaceability hotspots or distributions of high priority amphibian and reptile species.

\section{Supporting Information}

Table S1. Maximum annual dispersal distances of adult individuals recorded for Romanian reptiles and amphibians.

(DOCX)

Table S2. Evaluation of model predictive performance: average cross-validated Area Under the Curve (AUC) of the Receiver Operating Characteristic (ROC) for seven models used in ensemble modeling of amphibian and reptile distributions in Romania (ANN = artificial neural networks; CTA = classification tree analysis; $\mathbf{G A M}=$ generalized additive models; GBM = generalized boosted regression trees; MARS = multivariate adaptive regression splines; FDA = flexible discriminant analysis; $R F$ = random forests). (DOCX)

Table S3. Percent conservation target met by amphibians and reptiles in Romanian Natura 2000 sites under current and under future climate conditions (2020s and 2050s time horizons, emission scenarios A1B, A2A, and B2A) and dispersal assumptions ( LimD = limited dispersal; NoD = no dispersal); no-value cells represent species that are predicted to completely lose climate space.

(DOCX)

Table S4. Number of protected $10 \times 10 \mathrm{~km}$ grid cells where amphibian and reptile species meet the $40 \%$ conservation target under current and under future climate conditions (2020s and 2050s time horizons, emission scenarios A1B, $A 2 A$, and B2A) and dispersal assumptions ( LimD = limited dispersal; NoD = no dispersal); no-value cells represent species that are predicted to completely lose climate space.

(DOCX)

Table S5. Randomisations tests of differences between mean irreplaceability scores of Natura 2000 planning units and mean irreplaceability scores of randomly selected planning units under current and future climate conditions (2020s and 2050, three emission scenarios) under limited dispersal (LimD) and no dispersal (NoD) assumptions. (DOCX) 
Figure S1. Irreplaceability scores of planning units $(10 \times 10$ km grid cells) for 2020s (a) and (b) and 2050s (c) and (d) under limited-dispersal (LimD) and no-dispersal (NoD) assumptions.

(DOCX)

Figure S2. Future irreplaceability scores for emission scenarios A1B (a) and B2A (b) under constrained (left panels) and unconstrained (right panels) planning unit availability for the 2020s and 2050s time horizons and three emission scenarios, under limited (LimD) and no dispersal (NoD) assumptions.

(DOCX)

\section{References}

1. Jenkins CN, Joppa L (2009) Expansion of the global terrestrial protected area system. Biol Conserv 142: 2166-2174. doi:10.1016/ j.biocon.2009.04.016.

2. Soutullo A (2010) Extent of the global network of terrestrial protected areas. Conserv Biol 24: 362-363. doi:10.1111/j. 1523-1739.2010.01465.x. PubMed: 20491846.

3. Pressey RL, Cabeza M, Watts ME, Cowling RM, Wilson KA (2007) Conservation planning in a changing world. Trends Ecol Evol 22: 583-592. doi:10.1016/j.tree.2007.10.001. PubMed: 17981360.

4. Araújo MB, Cabeza M, Thuiller W, Hannah L, Williams PH (2004) Would climate change drive species out of reserves? An assessment of existing reserve-selection methods. Glob Chang Biol 10: 1618-1626. doi:10.1111/j.1365-2486.2004.00828.x.

5. Beale CM, Lennon JJ (2012) Incorporating uncertainty in predictive species distribution modelling. Philos Trans R Soc Lond B Biol Sci 367: 247-258. doi:10.1098/rstb.2011.0178. PubMed: 22144387.

6. Groves CR, Game ET, Anderson MG, Cross M, Enquist C et al. (2012) Incorporating climate change into systematic conservation planning Biodivers Conserv 21: 1651-1671. doi:10.1007/s10531-012-0269-3.

7. Hamann A, Aitken SN (2013) Conservation planning under climate change: accounting for adaptive potential and migration capacity in species distribution models. Divers Distrib 19: 268-280. doi:10.1111/j. 1472-4642.2012.00945.x.

8. Sinervo B, Méndez-de-la-Cruz F, Miles DB, Heulin B, Bastiaans E et al. (2010) Erosion of lizard diversity by climate change and altered thermal niches. Science 328: 894-899. doi:10.1126/science.1184695. PubMed: 20466932.

9. Hof C, Araújo MB, Jetz W, Rahbek C (2011) Additive threats from pathogens, climate and land-use change for global amphibian diversity. Nature 480: 516-U137. PubMed: 22089134.

10. Cox NA, Temple HJ (2009) European Red List of Reptiles. Luxembourg: Office for Official Publications of the European Communities.

11. Temple HJ, Cox NA (2009) European Red List of Amphibians Luxembourg: Office for Official Publications of the European Communities.

12. Davis AJ, Jenkinson LS, Lawton JH, Shorrocks B, Wood S (1998) Making mistakes when predicting shifts in species range in response to global warming. Nature 391: 783-786. doi:10.1038/35842. PubMed: 9486646 .

13. Aragón P, Rodríguez MA, Olalla-Tárraga MA, Lobo JM (2010) Predicted impact of climate change on threatened terrestrial vertebrates in central Spain highlights differences between endotherms and ectotherms. Anim Conserv 13: 363-373. doi:10.1111/j. 1469-1795.2009.00343.x.

14. Lawler JJ, Shafer SL, Blaustein AR (2010) Projected climate impacts for the amphibians of the Western Hemisphere. Conserv Biol 24: 38-50. doi:10.1111/j.1523-1739.2009.01403.x. PubMed: 20121840.

15. Araújo MB, Alagador D, Cabeza M, Nogués-Bravo D, Thuiller W (2011) Climate change threatens European conservation areas. Ecol Lett 14: 484-492. doi:10.1111/j.1461-0248.2011.01610.x. PubMed: 21447141.

16. Opermanis O, MacSharry B, Aunins A, Sipkova Z (2012) Connectedness and connectivity of the Natura 2000 network of protected areas across country borders in the European Union. Biol Conserv 153: 227-238. doi:10.1016/j.biocon.2012.04.031.

\section{Acknowledgements}

We thank W. Thuiller and D. Georges for advice on species distribution modeling. We also thank Scott M. Moody and two anonymous reviewers for thoughtful comments on a previous version of this manuscript.

\section{Author Contributions}

Conceived and designed the experiments: VDP LR. Performed the experiments: VDP LR IMN ALC. Analyzed the data: VDP LR. Contributed reagents/materials/analysis tools: DC IMN ALC. Wrote the manuscript: VDP LR DC IMN ALC.

17. loja Cl, Patroescu M, Rozylowicz L, Popescu VD, Verghelet M et al. (2010) The efficacy of Romania's protected areas network in conserving biodiversity. Biol Conserv143: 2468-2476. doi:10.1016/ j.biocon.2010.06.013.

18. Hochkirch A, Schmitt T, Beninde J, Hiery M, Kinitz T et al. (2013) Europe needs a new vision for a Natura 2020 network. Conservation. Letters: In press

19. Evans D (2012) Building the European Union's Natura 2000 network. Nat Conserv 1: 11-26. doi:10.3897/natureconservation.1.1808.

20. Kujala H, Moilanen A, Araújo MB, Cabeza M (2013) Conservation planning with uncertain climate change projections. PLOS ONE 8: e53315. doi:10.1371/journal.pone.0053315. PubMed: 23405068.

21. Burrows MT, Schoeman DS, Buckley LB, Moore P, Poloczanska ES et al. (2011) The pace of shifting climate in marine and terrestrial ecosystems. Science 334: 652-655. doi:10.1126/science.1210288. PubMed: 22053045.

22. Cogălniceanu D, Rozylowicz L, Stănescu $F$, Székely $P$, Samoilă $C$ et al. (2013). ivers Distrib Reptiles Romania Zookeys (In press)

23. Cogălniceanu D, Székely $P$, Samoilă C, losif R, Tudor M et al. (2013) Diversity and distribution of amphibians in Romania. Zookeys 296: 35-57. doi:10.3897/zookeys.296.4872. PubMed: 23794877.

24. Gruber B, Evans D, Henle K, Bauch B, Schmeller D et al. (2012) "Mind the gap!"-How well does Natura 2000 cover species of European interest? Nat Conserv 3: 45-62. doi:10.3897/natureconservation. 3.3732.

25. Cogălniceanu D, Tesio C (1993) On the presence of Rana lessonae in Romania. Amphibia Reptilia 14: 90-93. doi:10.1163/156853893X00237.

26. Hijmans RJ, Cameron SE, Parra JL, Jones PG, Jarvis A (2005) Very high resolution interpolated climate surfaces for global land areas. Int $J$ Climatol 25: 1965-1978. doi:10.1002/joc.1276.

27. Mitchell TD, Carter TR, Jones PD, Hulme M, New M et al. (2004). A comprehensive set of high-resolution grids of monthly climate for Europe and the globe: the observed record (1901-2000) and 16 scenarios (2001-2100). Working Paper 55 Norwich, UK: Tyndall Centre for Climate Change Research.

28. Tingley R, Herman TB (2009) Land-cover data improve bioclimatic models for anurans and turtles at a regional scale. J Biogeogr 36: 1656-1672. doi:10.1111/j.1365-2699.2009.02117.x.

29. Thuiller W, Lafourcade B, Engler R, Araujo MB (2009) BIOMOD - a platform for ensemble forecasting of species distributions. Ecography 32: 369-373. doi:10.1111/j.1600-0587.2008.05742.x

30. Core R Team (2012) R: A language and environment for statistical computing. Vienna, Austria ISBN 3-900051-07-0. Retrieved onpublished at whilst December year 1111 from http://www.Rproject.org/.

31. Liu CR, Berry PM, Dawson TP, Pearson RG (2005) Selecting thresholds of occurrence in the prediction of species distributions. Ecography 28: 385-393. doi:10.1111/j.0906-7590.2005.03957.x.

32. Fielding $A H$, Bell JF (1997) A review of methods for the assessment of prediction errors in conservation presence/absence models. Environ Conserv 24: 38-49. doi:10.1017/S0376892997000088.

33. Swets JA (1988) Measuring the accuracy of diagnostic systems. Science 240: 1285-1293. doi:10.1126/science.3287615. PubMed: 3287615 . 
34. Araújo MB, New M (2007) Ensemble forecasting of species distributions. Trends Ecol Evol 22: 42-47. doi:10.1016/j.tree. 2006.09.010. PubMed: 17011070

35. Marmion M, Parviainen M, Luoto M, Heikkinen RK, Thuiller W (2009) Evaluation of consensus methods in predictive species distribution modelling. Divers Distrib 15: 59-69. doi:10.1111/j. 1472-4642.2008.00491.x.

36. Coetzee BWT, Robertson MP, Erasmus BFN, van Rensburg BJ, Thuiller W (2009) Ensemble models predict Important Bird Areas in southern Africa will become less effective for conserving endemic birds under climate change. Glob Ecol Biogeogr 18: 701-710. doi:10.1111/j. 1466-8238.2009.00485.x.

37. Popescu VD, Hunter ML (2011) Clearcutting affects habitat connectivity for a forest amphibian by decreasing permeability to juvenile movements. Ecol Appl 21: 1283-1295. doi:10.1890/10-0658.1. PubMed: 21774430.

38. Zajitschek SRK, Zajitschek F, Clobert J (2012) The importance of habitat resistance for movement decisions in the common lizard, Lacerta vivipara. BMC Ecol 12: 13-. PubMed: 22827893.

39. Ferrier S, Pressey RL, Barrett TW (2000) A new predictor of the irreplaceability of areas for achieving a conservation goal, its application to real-world planning, and a research agenda for further refinement. Biol Conserv 93: 303-325. doi:10.1016/ S0006-3207(99)00149-4.

40. Pressey RL, Johnson IR, Wilson PD (1994) Shades of irreplaceability Towards a measure of the contribution of sites to a reservation goal. Biodivers Conserv 3: 242-262. doi:10.1007/BF00055941.

41. Pressey RL, Watts ME, Barrett TW, Ridges MJ (2008) The C-Plan conservation planning system: origins, applications, and possible futures. In: A MoilanenHP PossinghamKA Wilson. Spatial Conservation Prioritization. Oxford: Oxford University Press.

42. Pressey RL (2004) Conservation planning and biodiversity: Assembling the best data for the job. Conserv Biol 18: 1677-1681. doi:10.1111/j. 1523-1739.2004.00434.x.

43. Araújo MB, Lobo JM, Moreno JC (2007) The effectiveness of Iberian protected areas in conserving terrestrial biodiversity. Conserv Biol 21: 1423-1432. doi:10.1111/j.1523-1739.2007.00827.x. PubMed: 18173466.

44. Ord JK, Getis A (1995) Local spatial autocorrelation statistics distributional issues and an application. Geogr Anal 27: 286-306.

45. Zar JH (2010) Biostatistical analysis. Saddle River, NJ: Prentice Hall.

46. D'Amen M, Bombi P, Pearman PB, Schmatz DR, Zimmermann NE et al. (2011) Will climate change reduce the efficacy of protected areas for amphibian conservation in Italy? Biol Conserv 144: 989-997. doi: 10.1016/j.biocon.2010.11.004.

47. D'Amen M, Bombi $P$ (2009) Global warming and biodiversity: Evidence of climate-linked amphibian declines in Italy. Biol Conserv 142: 3060-3067. doi:10.1016/j.biocon.2009.08.004.

48. Araújo MB, Thuiller W, Pearson RG (2006) Climate warming and the decline of amphibians and reptiles in Europe. J Biogeogr 33: 17121728. doi:10.1111/j.1365-2699.2006.01482.x.

49. Williams JW, Jackson ST (2007) Novel climates, no-analog communities, and ecological surprises. Front Ecol Environ 5: 475-482. doi:10.1890/070037.

50. Williams JW, Jackson ST, Kutzbach JE (2007) Projected distributions of novel and disappearing climates by 2100 AD. Proc Natl Acad Sci U S A 104: 5738-5742. doi:10.1073/pnas.0606292104. PubMed: 17389402.

51. Deutsch CA, Tewksbury JJ, Huey RB, Sheldon KS, Ghalambor CK et al. (2008) Impacts of climate warming on terrestrial ectotherms across latitude. Proc Natl Acad Sci U S A 105: 6668-6672. doi:10.1073/pnas. 0709472105. PubMed: 18458348

52. Sunday JM, Bates AE, Dulvy NK (2011) Global analysis of thermal tolerance and latitude in ectotherms. Proc R Soc Lond B-Biol Sci 278: 1823-1830. doi:10.1098/rspb.2010.1295. PubMed: 21106582.

53. Cahill AE, Aiello-Lammens ME, Fisher-Reid MC, Hua X, Karanewsky CJ et al. (2013) How does climate change cause extinction. Proc R Soc Lond B Biol Sci 280.

54. Räsänen K, Laurila A, Merilä J (2003) Geographic variation in acid stress tolerance of the Moor Frog, Rana arvalis. I. Local adaptation. Evolution 57: 352-362. doi: 10.1554/0014-3820(2003)057[0352:GVIAST]2.0.CO;2. PubMed: 12683531.

55. Skelly DK (2004) Microgeographic countergradient variation in the wood frog, Rana sylvatica. Evolution 58: 160-165. doi:10.1554/03-425. PubMed: 15058728

56. Lindsey HA, Gallie J, Taylor S, Kerr B (2013) Evolutionary rescue from extinction is contingent on a lower rate of environmental change. Nature 494: 463-467. doi:10.1038/nature11879. PubMed: 23395960.

57. Atkins KE, Travis JMJ (2010) Local adaptation and the evolution of species' ranges under climate change. J Theor Biol 266: 449-457. doi: 10.1016/j.jtbi.2010.07.014. PubMed: 20654630.

58. Millar Cl, Stephenson NL, Stephens SL (2007) Climate change and forests of the future: Managing in the face of uncertainty. Ecol Appl 17: 2145-2151. doi:10.1890/06-1715.1. PubMed: 18213958.

59. Rozylowicz L, Popescu VD, Patroescu M, Chisamera G (2011) The potential of large carnivores as conservation surrogates in the Romanian Carpathians. Biodivers Conserv 20: 561-579. doi:10.1007/ s10531-010-9967-x

60. Knorn J, Kuemmerle T, Radeloff VC, Szabo A, Mindrescu M et al. (2012) Forest restitution and protected area effectiveness in postsocialist Romania. Biol Conserv 146: 204-212. doi:10.1016/j.biocon. 2011.12.020.

61. Pătru-Stupariu I, Angelstam P, Elbakidze M, Huzui A, Andersson K (2013) Using spatial patterns and forest history to identify potential high conservation value forests in Romania. Biodiv Conserv 22: 2023-2039. doi:10.1007/s10531-013-0523-3.

62. Hartel T, Schweiger O, Ollerer K, Cogalniceanu D, Arntzen JW (2010) Amphibian distribution in a traditionally managed rural landscape of Eastern Europe: Probing the effect of landscape composition. Biol Conserv 143: 1118-1124. doi:10.1016/j.biocon.2010.02.006.

63. Müller D, Kuemmerle T, Rusu M, Griffiths P (2009) Lost in transition: determinants of post-socialist cropland abandonment in Romania. J Land Use Sci 4: 109-129. doi:10.1080/17474230802645881.

64. Kuemmerle T, Müller D, Griffiths P, Rusu M (2009) Land use change in Southern Romania after the collapse of socialism. Reg Environ Change 9: 1-12. doi:10.1007/s10113-008-0050-z.

65. Bălteanu D, Popovici E-A (2010) Land use changes and land degradation in Romania. Romanian. J Geogr 54: 95-105.

66. Kareiva P, Marvier M (2007) Conservation for the people. Sci Am 297: 50-57. doi:10.1038/scientificamerican1107-50. PubMed: 17926754.

67. Fischer J, Hartel T, Kuemmerle T (2012) Conservation policy in traditional farming landscapes. Conserv Lett 5: 167-175. doi:10.1111/j. 1755-263X.2012.00227.x.

68. Rozylowicz L, Popescu VD (2013) Habitat selection and movement ecology of Eastern Hermann's tortoises in a rural Romanian landscape. Eur J Wildl Res 59: 47-55. doi:10.1007/s10344-012-0646-y. 